\title{
Nitroarylurea-terminated supramolecular polymers that exhibit facile thermal repair and aqueous swelling-induced sealing of defects
}

Article

Accepted Version

Creative Commons: Attribution-Noncommercial-No Derivative Works 4.0

Baker, B. C., German, I. M., Chippindale, A. M., Mcewan, C. E. A., Stevens, G. C., Colquhoun, H. M. and Hayes, W. (2018) Nitroarylurea-terminated supramolecular polymers that exhibit facile thermal repair and aqueous swelling-induced sealing of defects. Polymer, 140. pp. 1-9. ISSN 0032-3861 doi: https://doi.org/10.1016/j.polymer.2018.02.029 Available at https://centaur.reading.ac.uk/75554/

It is advisable to refer to the publisher's version if you intend to cite from the work. See Guidance on citing.

To link to this article DOI: http://dx.doi.org/10.1016/j.polymer.2018.02.029

Publisher: Elsevier

All outputs in CentAUR are protected by Intellectual Property Rights law, including copyright law. Copyright and IPR is retained by the creators or other copyright holders. Terms and conditions for use of this material are defined in the End User Agreement. 


\section{www.reading.ac.uk/centaur}

\section{CentAUR}

Central Archive at the University of Reading

Reading's research outputs online 


\title{
Nitroarylurea-terminated supramolecular polymers that exhibit facile thermal repair and aqueous swelling-induced sealing of defects
}

\author{
Benjamin C. Baker ${ }^{a}$; Ian M. German ${ }^{b}$; Ann M. Chippindale ${ }^{a}$; Corinne E. A. McEwan ${ }^{a}$; Gary C. Stevens ${ }^{b}$; \\ Howard M. Colquhoun ${ }^{a}$; and Wayne Hayes ${ }^{a *}$ \\ a Department of Chemistry, University of Reading, Whiteknights, Reading, RG6 6AD, UK. Email: \\ w.c.hayes@reading.ac.uk, Telephone: +44 118378 6491, Fax: +44 1183786331

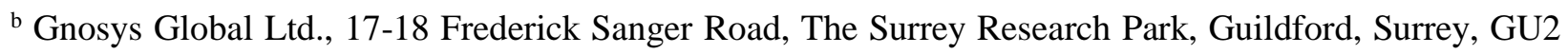 \\ $7 \mathrm{YD}, \mathrm{UK}$
}

\begin{abstract}
Bi- and tri-armed polyethylene glycol units endcapped with nitroaryl urea units have been synthesised. These endcapped polymers are able to self-assemble via complementary supramolecular interactions, specifically urea-urea and nitro-urea hydrogen bonding, to afford materials with dramatically increased mechanical and thermal properties when compared to those of the uncapped polyethylene glycol precursors. Thin films of the capped polymeric systems are able to self-repair following defect creation. Control over the mechanical and thermal characteristics (in terms of bulk viscosity) of the self-assembled networks was achieved by varying the proportion of tri-armed to bi-armed self-assembly units included in the polymer. These systems demonstrate water absorption and swelling capabilities that are also controllable by varying the ratio of the two types of unit. These physical properties have been optimised to realise a secondary pathway to puncture-repair as a result of swelling on water contact.
\end{abstract}

Keywords: Healable Polymer; Supramolecular Network; hydrogen bonding

\section{Introduction}

A number of high-performance polymers have been recognised as suitable for use in important but inaccessible protection systems such as the insulation layers of transoceanic cables. ${ }^{1}$ Most submarine and underground cables use materials that are commonly based on high density polyethylene in cable sheath applications (crosslinked polyethylene for electrical insulation). Damage to the cable sheath protection 
layers can often result in system failure. ${ }^{2-14}$ Self-repair capability would thus be a very desirable quality in such materials, to prevent system failure and so avoid costly replacement. ${ }^{2-10}$ Routes to repairable polymeric systems have been developed through several different approaches including the use of reversible or irreversible covalent bond formation, ${ }^{4-6,15}$ encapsulation of healing agents ${ }^{7}$ and the directed application of supramolecular self-assembly. ${ }^{8-10,12-14,16}$ Of these routes, the supramolecular approach (involving the positioning of sacrificial but reversible supramolecular interactions within a covalently bound polymeric network) can involve the use of either hydrogen bonds, metal-ligand interactions, ionic interactions, aromatic $\pi-\pi$ stacking, or a combination of such motifs, and has enabled the development of many diverse, repairable systems. ${ }^{8-10,12-14,16}$ These "supramolecular polymers" have a distinct advantage over healing systems involving irreversible covalent bonds in that repeated break-heal cycles can be realised via stimuli such as heat, time, pressure, light or ultrasound. ${ }^{11,17-19}$

For self-healing supramolecular polymer systems, relatively few studies have focused upon the impact of water contact as either a positive or negative aspect of the repair process..$^{20,21}$ Water contact can, in principle, lead to degradation of the supramolecular polymer network, diminished binding to polar, supramolecular binding sites, or reorientation of polar groups away from the fracture-surface to make supramolecular healing unachievable. ${ }^{22-25}$ By considering the environment in which remote protection systems will be embedded (e.g. soil, concrete or seawater), the probability of contact with water must be incorporated into the system design. ${ }^{8-10,12-14,20-25}$ Several materials have been described that utilise a dynamic polymer response on contact with water to enable repair under aqueous conditions. ${ }^{20,26}$ Here we report a novel approach to defect-sealing that employs water-induced swelling of a supramolecular polymer matrix. ${ }^{27}$

In designing supramolecular polymeric networks that can self-repair under aqueous conditions it was decided to exploit the previously reported 3-nitroaryl-urea motif (Scheme 1). ${ }^{28-30}$ This recognition unit was used as the endcapping group for an oligomeric, liquid linker, namely polyethylene glycol (PEG, $\mathrm{M}_{\mathrm{n}} \approx 600$ $\mathrm{g} / \mathrm{mol}$ ) and was found to afford materials with enhanced mechanical and thermal properties relative to the parent oligomer. ${ }^{30,31}$ It was proposed that when the endcapped PEG is subject to sufficient force to effect mechanical damage, the weak non-covalent bonds between the endcapping units will be disrupted, enabling the liquid PEG to flow and thus refill the void created. Subsequent re-establishment of hydrogen bonds between the endcapping units leads to self-assembly of a new network and, ultimately, recovery of the system's mechanical strength (Scheme 1). ${ }^{11-14}$ Formation of tri-armed oligomeric systems end-capped with this recognition unit led to increased mechanical strength - relative to the corresponding two-armed system - by enhancing the effective cross-linking density ${ }^{32}$ through supramolecular interactions. ${ }^{30}$ Furthermore, the water-absorption properties of the PEG linking units are able to induce swelling, ${ }^{27}$ and so facilitate defect closure after water contact with the new materials. ${ }^{7,11,27}$ 
A)

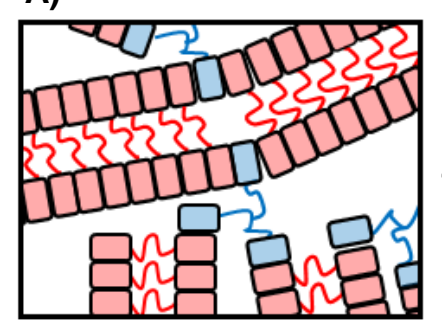

B)

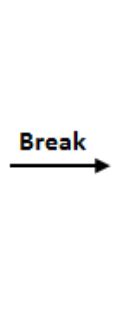

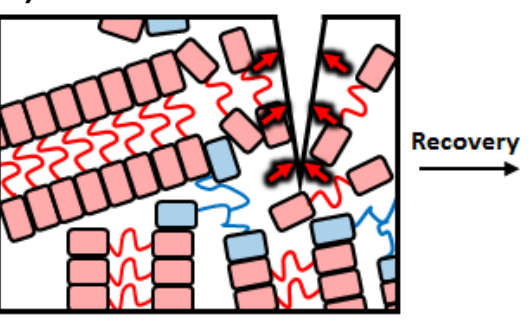

C)

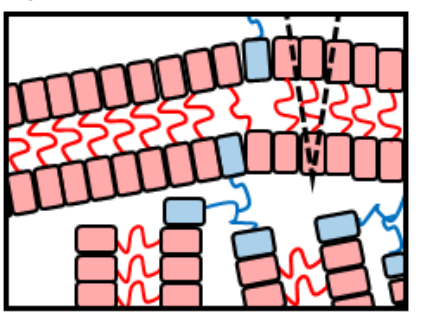

Where
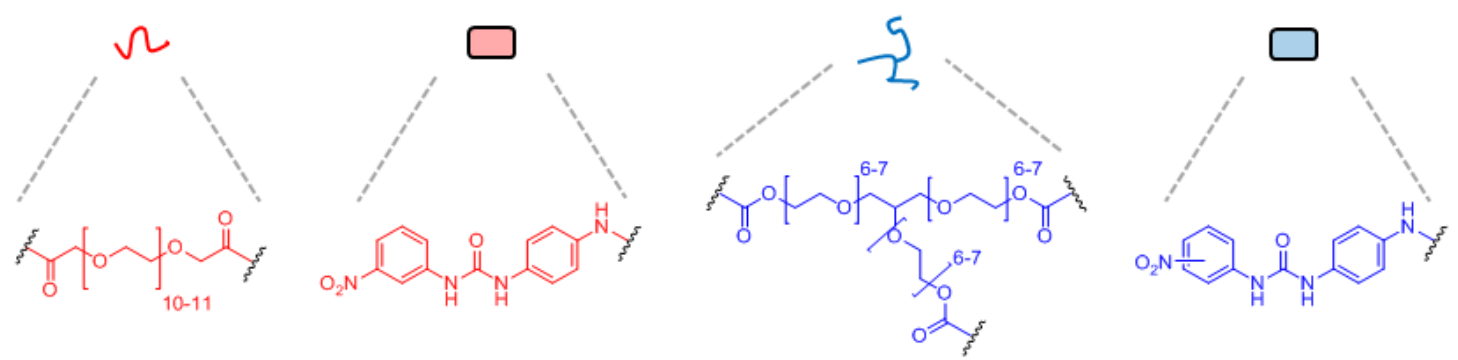

Scheme 1. A) Proposed organisation of the nitroaryl-urea motif linked to both bi- and tri-armed polyethylene glycol units to yield a network in the pristine material; B) material after damage resulting in network break up, and C) the concept of oligomer flow and re-association of the endcapping recognition units leading to recovery of the network in the bulk for swelling induced recovery (see Scheme 2).

\section{Results and Discussion}

In order to achieve the targeted supramolecular assemblies (Scheme 1), linked nitroaryl-urea units were designed based upon the success of previously-synthesised gelators. ${ }^{30}$ In this study, the selected linkers were poly(ethylene glycol) bis(carboxymethyl) ether $\left(\mathrm{M}_{\mathrm{n}} \sim 600\right)$ (affording bis-functionalised PEG 1 ) and glycerol ethoxylate (affording tri-functionalised PEGs 2-3, Figure 1) (for the synthetic schemes see Supplementary Information (SI), Schemes S1 and S2). These PEG-based materials were chosen for their water absorbent characteristics at room temperature and successful application in other repairable systems. ${ }^{8-10,27,31-33}$ The functionalised PEGs 4-6 (Figure 1) were also synthesised as benchmark materials, to evaluate the specific importance of the nitroarylurea motif to self-assembly. 

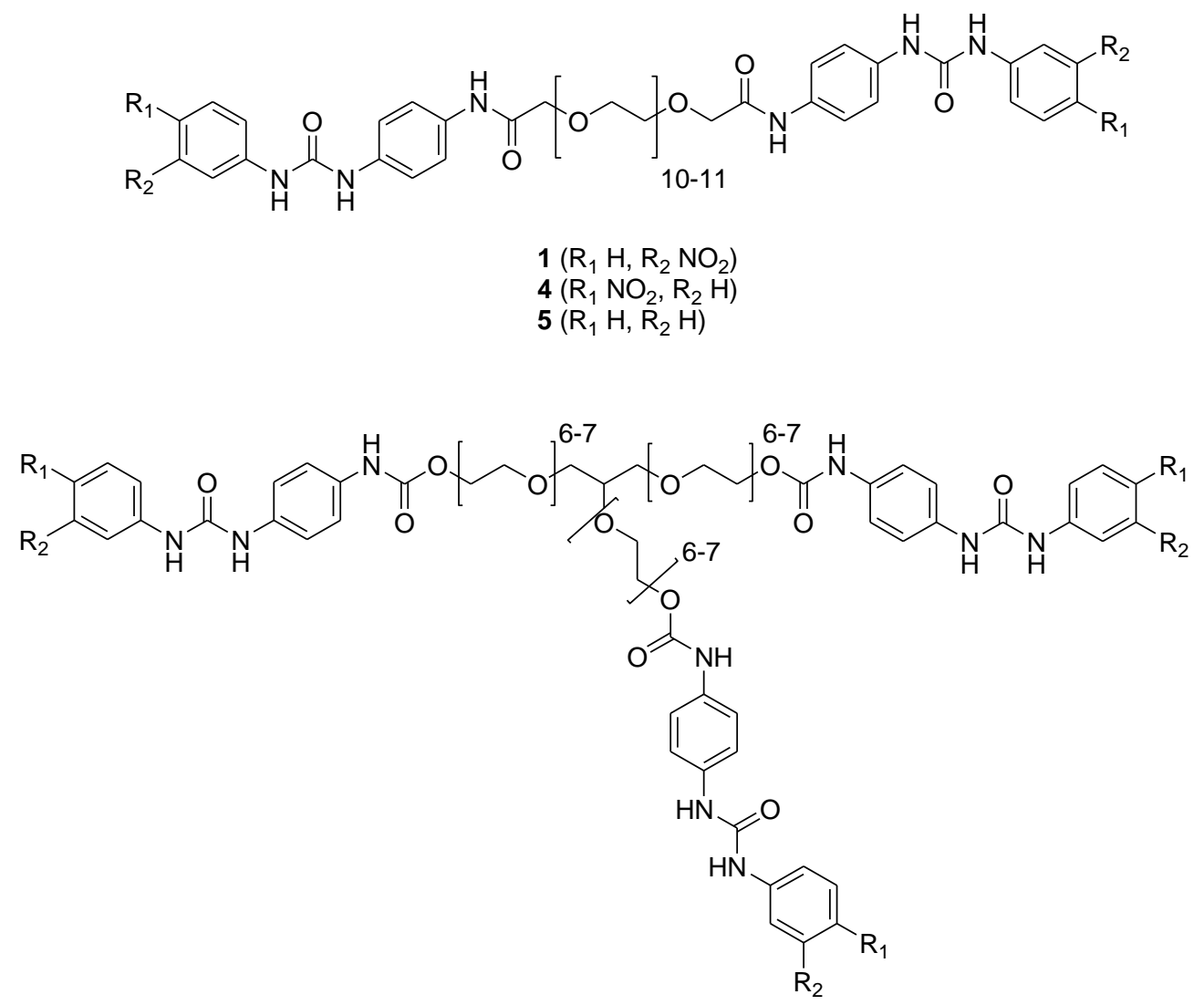

$2\left(\mathrm{R}_{1} \mathrm{H}, \mathrm{R}_{2} \mathrm{NO}_{2}\right)$

$3\left(\mathrm{R}_{1} \mathrm{NO}_{2}, \mathrm{R}_{2} \mathrm{H}\right)$

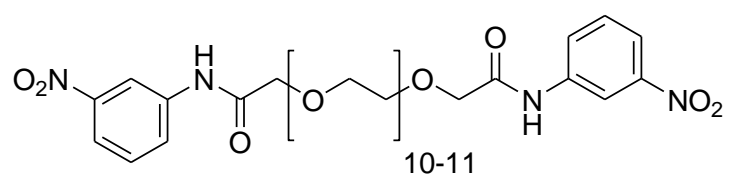

6

Figure 1. Bi- and tri-functionalised PEGs 1-6 featuring nitroaryl-urea or aryl-amide units.

Bi-functionalised PEGs 1 and 4-6 were synthesised in good yields (>66 \%). In each case the aminefunctional aromatic end-cap was dissolved in dry tetrahydrofuran containing triethylamine and the diacyl chloride of poly(ethylene glycol) bis(carboxymethyl) ether $\left(M_{n} \sim 600\right)^{32}$ was then added. The structures of the bi-functionalised PEGs were confirmed via a range of analytical techniques (for the analytical data on the polymers report in this paper see SI, Figures S1-16). As an example, ${ }^{1} \mathrm{H}$ NMR spectroscopic analysis of 1 demonstrated the absence of the amine resonances (which would have been evident at $4.87 \mathrm{ppm}$ ) associated with the starting materials ${ }^{30}$ in conjunction with the appearance of amide resonances (observed at $9.54 \mathrm{ppm}$, see SI Figure S1) resulting from formation of the target amide linker. Additional evidence for 
the formation of 1 was provided by ${ }^{13} \mathrm{C}$ NMR spectroscopy which revealed the presence of two carbonyl resonances (at 167.8 and $152.5 \mathrm{ppm}$ ) associated, respectively, with the urea and amide carbonyl groups, and the absence of any carboxylic acid resonance (171.6 ppm) associated with the starting material. These NMR data were complemented by infra-red spectroscopic analysis, which showed two distinct carbonyl stretching absorptions at 1753 and $1657 \mathrm{~cm}^{-1}$. Thermal (DSC) analysis revealed a glass transition at $-10{ }^{\circ} \mathrm{C}$ (see SI Figure S25) which was not evident for the uncapped poly(ethylene glycol) bis(carboxymethyl) ether $\left(\mathrm{M}_{\mathrm{n}} \sim 600\right){ }^{34}$

The tri-functionalised PEGs $\mathbf{2}$ and $\mathbf{3}$ were synthesised via a three-stage reaction. 4-Nitrophenylisocyanate was added to glycerol ethoxylate $\left(M_{n} \sim 1000\right)$ in THF and the product thus formed was reduced with hydrogen (Pd-C catalyst) to yield an amine-capped tri-armed intermediate. To this tri-armed amine, either 3 or 4-nitrophenyl isocyanate was added to afford $\mathbf{2}$ and $\mathbf{3}$, respectively. The successful synthesis of the trifunctionalised PEGs $\mathbf{2}$ and $\mathbf{3}$ was confirmed by ${ }^{1} \mathrm{H}$ NMR spectroscopic analysis of $\mathbf{3}$, which showed the key amidic proton resonances at $8.71 \mathrm{ppm}$ (see SI Figure S2). Two distinct carbonyl stretching absorptions were evident in the IR spectrum (at 1719 and $1653 \mathrm{~cm}^{-1}$ ), assigned to the amide and urea residues, respectively (see SI Figure S11). Analysis by DSC revealed a glass transition at $-9{ }^{\circ} \mathrm{C}$ (that was not evident in the glycerol ethoxylate starting material).

Previous gelation studies on low molecular weight hydro- and organogelators have demonstrated the importance of meta-substitution of the nitro group on self-assembling units containing nitroaryl ureas (see compound 1, Figure 1). ${ }^{29,30}$ Computational modelling of previously reported ${ }^{29,30}$ self-assembling gelators that feature the meta and para nitro end groups present in $\mathbf{1}$ and $\mathbf{4}$ was undertaken (see SI Figure S17). This revealed the geometrically-specific interactions between the meta nitro-urea moieties (present in 1) that permit one dimensional, extended fibrillar growth (rather than the disjointed assembly pattern of $\mathbf{4}$ which possesses only para nitro moieties). In addition, we were able to carry out single crystal X-ray crystallographic analysis of the end groups used in molecule 1 (e.g. [1-(4-aminophenyl)-3-(3nitrophenyl)urea] (7, Figure 2A). Crystals of $\mathbf{7}$ suitable for X-ray crystallographic analysis were grown by slow evaporation from solution in THF and the solid state data are presented in the SI (Figure S18 and Table S1). Three key hydrogen bonds between adjacent molecules in the crystal were identified, involving the urea, nitro and amino groups: $\mathrm{N}(1) \cdots \cdot \mathrm{N}(2), 3.068 \AA, \mathrm{N}(2) \cdots \bullet \mathrm{O}(2), 3.212 \AA$ and $\mathrm{N}(3) \cdots \bullet \mathrm{O}(1), 2.875 \AA$, respectively; see B/C in Figure 2. Interestingly, intermolecular hydrogen bonding between the nitro and urea moieties, reported previously in structurally related systems, ${ }^{35,36}$ was not observed in the case of the end group unit (7), although hydrogen bonds were observed between the amine moiety (not present in chain-end structures due to its role in chain-end modification reactions), and both the nitro and urea groups, with the amine acting simultaneously as both hydrogen bond donor and acceptor (C, Figure 2). ${ }^{37}$ 
A)<smiles>Nc1ccc(NC(=O)Nc2cccc([N+](=O)[O-])c2)cc1</smiles>

7

B)

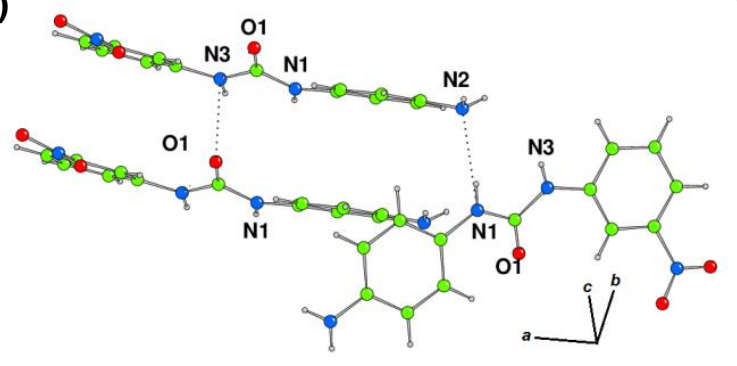

C)

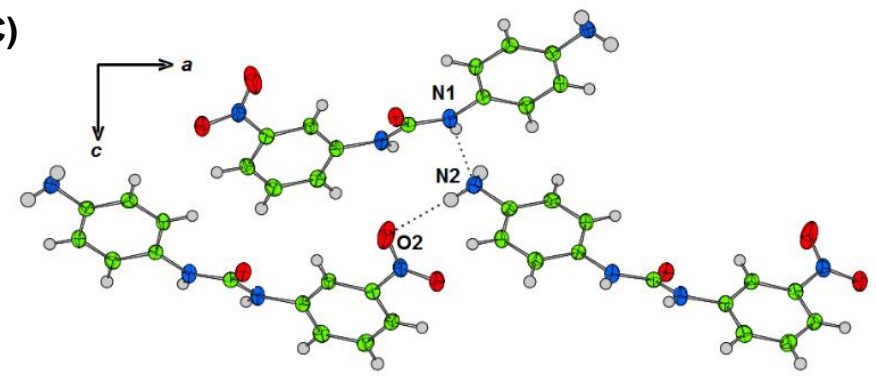

Figure 2. A) Nitroaryl urea end group [1-(4-aminophenyl)-3-(3'-nitrophenyl)urea] (7). B) Corresponding crystal structure, showing hydrogen bonds between atoms N1 and N2, and N3 and O1, in adjacent molecules. Distances $\mathrm{N} 1 \cdots \mathrm{N} 2$ and $\mathrm{N} 3 \cdots \mathrm{O} 1$ are 3.068 and $2.875 \AA$, respectively, C) view along the $b$ axis showing distances between $\mathrm{N} 1$ and N2, and N2 and O1, in adjacent molecules. Distances N2•••O1 are 3.068 and $3.212 \AA$, respectively.

In order to quantify the degree of self-assembly, NMR dilution studies of functionalised PEG 1 were undertaken in $\mathrm{CDCl}_{3}$ (see SI Figures S19-20). Shifts in the proton resonance associated with the urea group of molecule $\mathbf{1}$, as a function of concentration, were used to determine association constants $\left(K_{\mathrm{a}}\right)$. Data were analysed using the least squares regression analysis software Dynafit, ${ }^{38}$ from Biokin, and yielded a $K_{\mathrm{a}}$ value of $130 \pm 20 \mathrm{M}^{-1}$, significantly lower than those values reported for hydrogen-bonded, repairable systems from the research groups of Meijer ${ }^{39}$ and Lehn ${ }^{40}$ though it is noted that the number of hydrogen bonds per unit are fewer in the case of the bis aryl urea present in 1-4.

To assess the mechanical and adhesive characteristics of functionalised PEGs 1-6 and their blends, films of the oligomers (averaging $5 \times 9 \times 1 \mathrm{~mm}$ ) were cast onto glass slides backed with grid paper. The slides were then mounted vertically in order to monitor polymer flow under gravity over time $\left(20{ }^{\circ} \mathrm{C}\right.$, atmospheric conditions) (See SI Figures S21-24). Films of the bi-functionalised PEG 1 showed distinct enhancement of mechanical properties when compared to unfunctionalised polyethylene glycol bis(carboxymethyl)ether. Thus the functionalised PEGs did not flow visibly over a period of four months, whereas the latter film 
flowed immediately at $20^{\circ} \mathrm{C}$ when the slide was fixed in the vertical position (see $\mathbf{A}$ and $\mathbf{B}$ in Figure 3). At higher temperatures $\left(35^{\circ} \mathrm{C}\right)$ the mechanical stability of films of $\mathbf{1}$ decreased sharply. In an attempt to overcome this fall-off in mechanical properties with temperature, films of blends of $\mathbf{1}$ with the trifunctionalised PEGs 2 and $\mathbf{3}$ (1:1 wt ratio) were cast and their physical characteristics assessed. ${ }^{31-32}$ The latter films exhibited improved mechanical stability in comparison to the bi-functionalised PEG 1, with temperatures $\geq 65^{\circ} \mathrm{C}$ required to initiate flow (see $\mathbf{C}$ in Figure 3).

A)

Unfunctionalised PEG

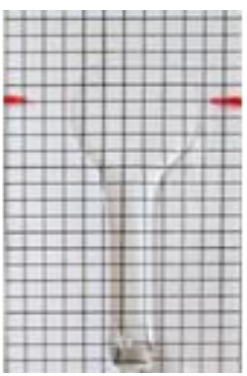

$20^{\circ} \mathrm{C}$

$10 \mathrm{~min}$
B)

Bi-functionalised PEG

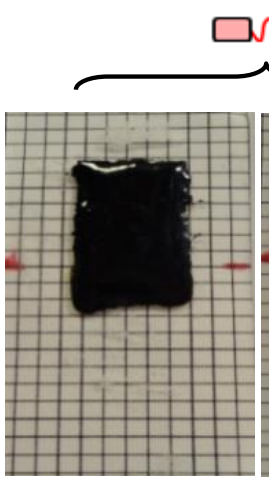

$20^{\circ} \mathrm{C}$

4 months
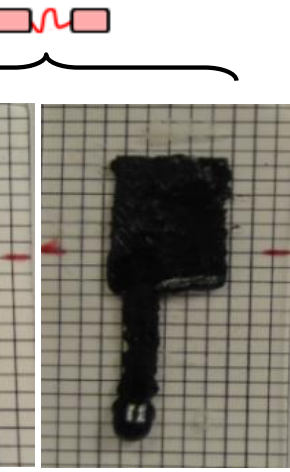

$35^{\circ} \mathrm{C}$

72 hours
C)

$\mathrm{Bi}$ - and tri-functionalised PEG

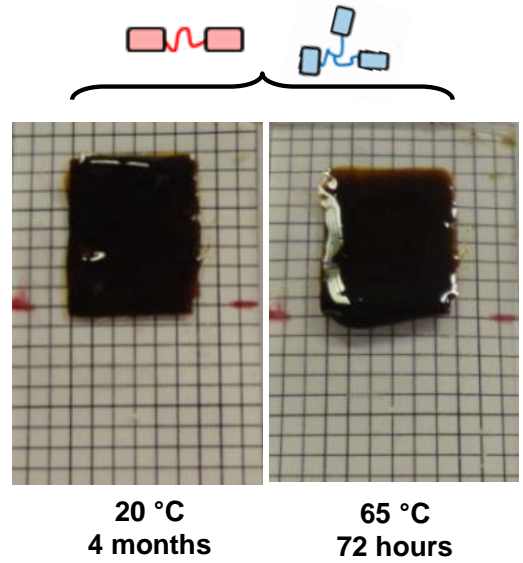

Figure 3. Films cast onto glass slides and then held in the vertical position: A) polyethylene glycol bis(carboxymethyl) ether $\left(M_{n} \sim 600\right) 10$ minutes after casting; B) 1 at 4 months after casting and 72 hours after being held at $35^{\circ} \mathrm{C}$; $)$ cast of 1 and 3 blend (1:1 wt ratio) 4 months after casting, and after 72 hours at $65^{\circ} \mathrm{C}$. Each film was formed via melt casting, being held at approximately 20 minutes at $70{ }^{\circ} \mathrm{C}$ and compressed to give average film dimensions $5 \times 9 \times 1$ $\mathrm{mm}$. Grid paper behind the slides has a $1 \times 1 \mathrm{~mm}$ square-size.

None of the benchmark bi-armed functionalised PEGs (i.e. 4-6, see Figure 1) exhibited the mechanical stability shown in casts of 1-3 (polymer flow in 4-6 was often realised in $<1$ week, see SI). Functionalised PEGs without the nitro functionality (5) and without the secondary aromatic moiety (6) flowed at $20{ }^{\circ} \mathrm{C}$ (in $<7$ days) (see SI Figure 24). Interestingly the bi-armed functionalised PEG with the nitro moiety in the para position (4, Figure 1) formed a film rather than a granular solid as expected from three dimensional growth (see previous studies on analagous low weight molecular gelators ${ }^{29,30}$, SI Figure S17). However this film also proved to be unstable (see SI Figure S24) highlighting the need for the specific hydrogen bonding interactions between meta nitro and urea groups to produce effective self-assembly (Figures $\mathbf{2}$ and $\mathbf{3}$ and SI Figure S17).

To assess the impact of supramolecular crosslinking on the thermal stability of networks formed from blends of the bi-functionalised PEG 1 and tri-functionalised PEGs 2/3, DSC analysis was undertaken to determine the change in the glass transition temperature $\left(T_{g}\right)$ as a function of the percentage weight of the 
individual tri-armed component added (Figure 4). This analysis revealed that increasing the percentage weight of the meta nitro tri-armed functionalised PEG 2 (with respect to $\mathbf{1}$ ) resulted in a direct increase in the $\mathrm{T}_{\mathrm{g}}$ (from -10 to $0{ }^{\circ} \mathrm{C}$ ). This trend correlates with an increased degree of covalent crosslinking (via addition of the triarmed units) within the supramolecular network. ${ }^{32}$ Interestingly, thermal analysis of blends of bi-functionalised PEG 1 with tri-functionalised PEG 3 revealed a parabolic relationship between the blend composition and $\mathrm{T}_{\mathrm{g}}$ (with a maximum observed at $3{ }^{\circ} \mathrm{C}$ ). The difference in thermal property impact is attributed to the location of the nitro moiety, i.e. meta or para to the urea unit. This structural effect was also apparent in healing studies (see below) and in agreement with previous self-assembly gelation studies. ${ }^{30}$

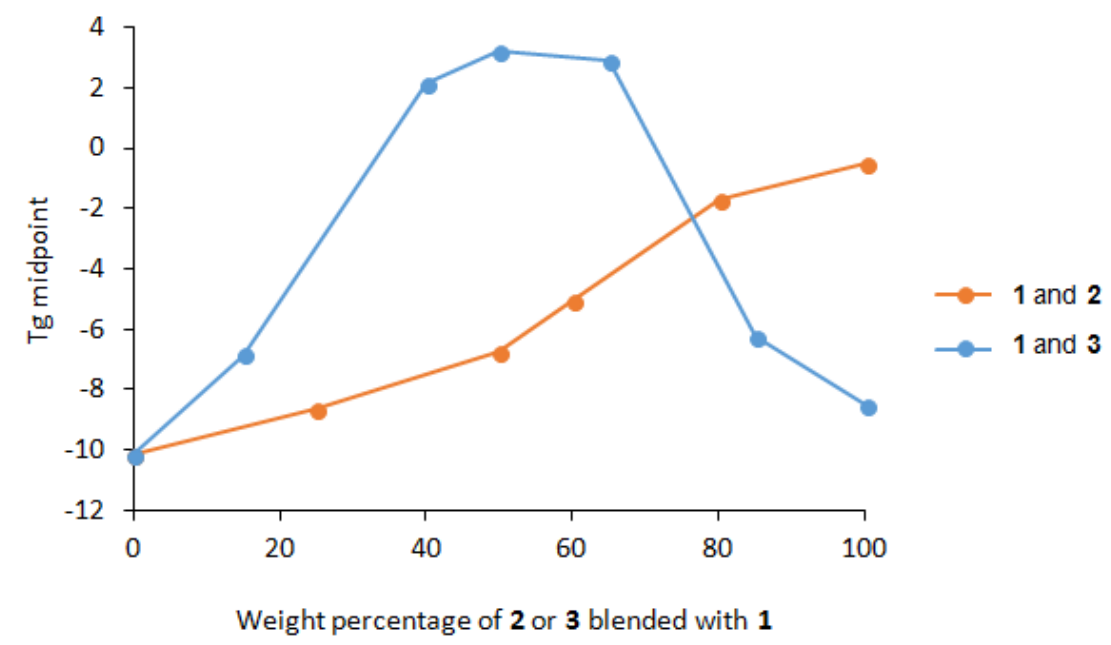

Figure 4. Plot of $T_{g}$ (DSC midpoints) versus the percentage weight of tri-functionalised PEGs $\mathbf{2}$ or $\mathbf{3}$ blended with bifunctionalised PEG 1.

To investigate the possibility of healing films of $\mathbf{1}$, rheological studies were undertaken for which the bifunctionalised PEG 1 was cast directly onto rheometer plates and the temperature was increased progressively from 0 to $60{ }^{\circ} \mathrm{C}$ during rheometric measurements (parallel plate geometry, $1 \%$ strain, heating rate $2{ }^{\circ} \mathrm{C} / \mathrm{min}$ ). It was found that the viscoelastic transition occurred at $26{ }^{\circ} \mathrm{C}$ (Figure 5), and the rheological data suggest that this material could be healed at temperatures close to ambient. ${ }^{16}$ In contrast, the films cast from combinations of the bi-functionalised PEG 1 and the tri-functionalised PEGs $\mathbf{2}$ or $\mathbf{3}$ proved to be too viscous at all temperatures studied $\left(0-100{ }^{\circ} \mathrm{C}\right)$ for comparative rheological analyses to be obtained. 


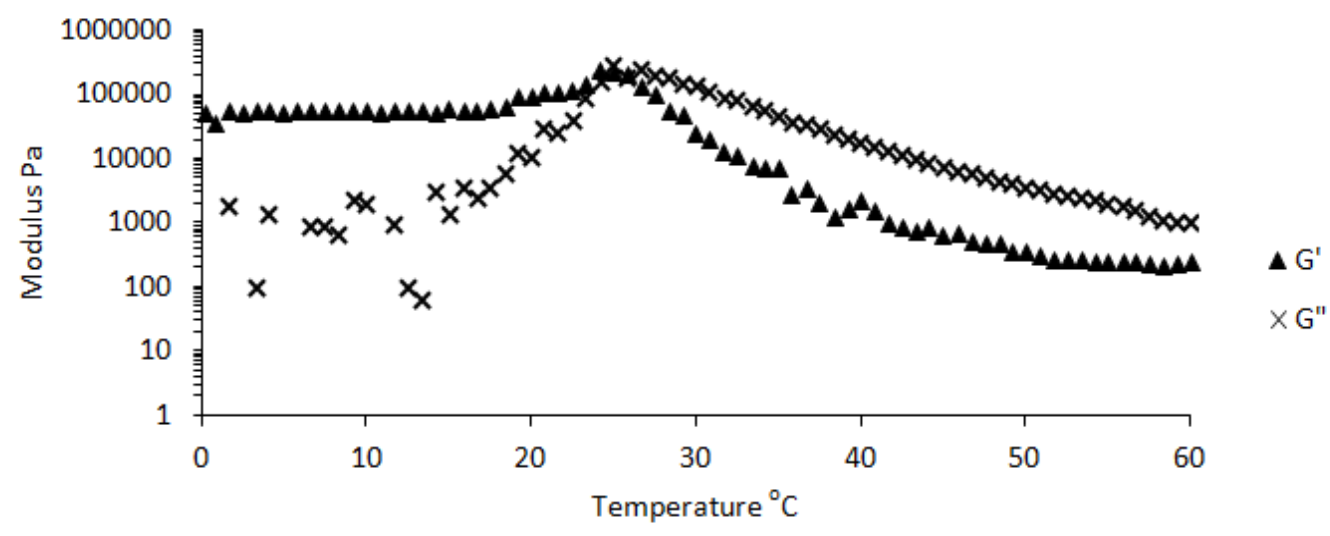

Figure 5. Temperature dependent storage (G') and loss modulus (G”) of bi-functionalised PEG 1, obtained using a rotating plate rheometer, with the crossover of $G^{\prime}$ and $G$ ” evident at $26{ }^{\circ} \mathrm{C}$. Note that films containing the PEG oligomers $\mathbf{2}$ and $\mathbf{3}$ proved to be too viscous for comparative rheological analysis.

Of significant interest was the visual observation of the healing process in thin films of the bi- functionalised PEG 1 (averaging $5 \times 9 \times 1 \mathrm{~mm}$ ). Films were cast onto glass slides and defects (cuts) were introduced using a scalpel. Rapid closure and healing of the cuts ( $<30$ minutes) was observed, even at room temperature $\left(20^{\circ} \mathrm{C}\right)$.
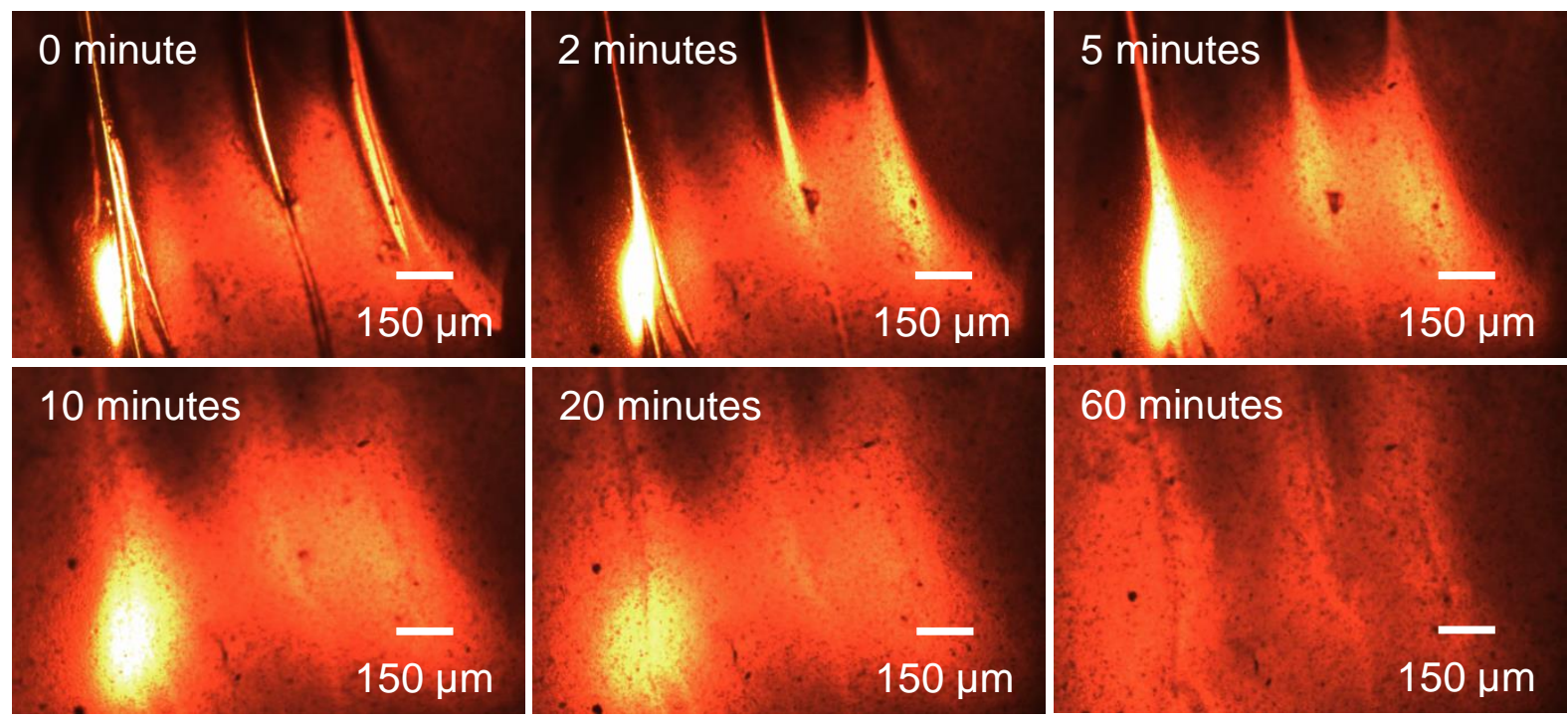

Figure 6. Optical micrographs showing spontaneous healing over time of a film of the blend of functionalised PEGs $\mathbf{1}$ and $\mathbf{3}$ (1:1 wt ratio) (average film dimensions $5 \times 9 \times 1 \mathrm{~mm}$ ) at $20{ }^{\circ} \mathrm{C}$ after damage (4 cuts created with a surgical scalpel). 
Furthermore, films of the blends of functionalised PEGs 1 and $\mathbf{3}$ (1:1 wt ratio) demonstrated equally good self-repair properties at $20^{\circ} \mathrm{C}$ (Figure 6) as well as increased thermal and mechanical stability (with respect to an increased resistance and a higher thermal barrier to flow, Figures 3 and 4). These results suggest that supramolecular associations, and not just flow, lead to defect repair and healing in the present systems. It is noted these results were repeatable on inversion of the samples, without apparent flow and disruption of the covering.

Interestingly, the blends of functionalised PEGs 1 and $\mathbf{2}$ (1:1 wt ratio) did not demonstrate healing properties at $20^{\circ} \mathrm{C}$, and closure of cuts was not observed even when heated to $200{ }^{\circ} \mathrm{C}$ (above the viscoelastic transition of 1, Figure 5). Analysis of films of the tri-armed functionalised PEG 2 showed no evidence of self-repair over a range of times and temperatures, but defect closure did occur at $45-50{ }^{\circ} \mathrm{C}$ in films of the tri-armed functionalised PEG 3 (above the viscoelastic transitions, Figure 3).

Further healing studies were conducted to measure the impact of the presence of water on the functionalised PEGs. Thermogravimetric analysis was used to monitor the water absorption capabilities of the functionalised PEGs, $\mathbf{1}$ and 3, which had also demonstrated healing abilities. Films of $\mathbf{1}, \mathbf{3}$ and blends of $\mathbf{1}$ and 3 (1:1 wt. ratio blend) were equilibrated simultaneously with atmospheric moisture for a period of 21 days thus ensuring exposure to identical environmental conditions, including atmospheric humidity (the temperature of the laboratory was $20^{\circ} \mathrm{C}$ ). Samples were removed at regular intervals and analysed by TGA to determine the percentage of water absorbed. This was measured as the percentage weight loss over the range $25-100{ }^{\circ} \mathrm{C}$, at a heating rate of $2{ }^{\circ} \mathrm{C} / \mathrm{min}$. The bi-functionalised PEG 1 absorbed a substantially greater quantity of water over this period, and at a faster rate, than the tri-functionalised PEG 3. This result is consistent with increase in the degree of covalent crosslinking, within the supramolecular networks on progressing from bi- to tri-armed oligomers as well as an increase in the fraction of hydrophobic material by weight (reducing the overall content of the PEG backbone). Interestingly, films formed of blends of $\mathbf{1}$ and 3 (1:1 wt. ratio) exhibited a faster rate of water pick-up compared to films of $\mathbf{3}$, yet far less overall water absorption than films of 1 over the same time period (21 days) (Figure 7, see SI Figure S34). 


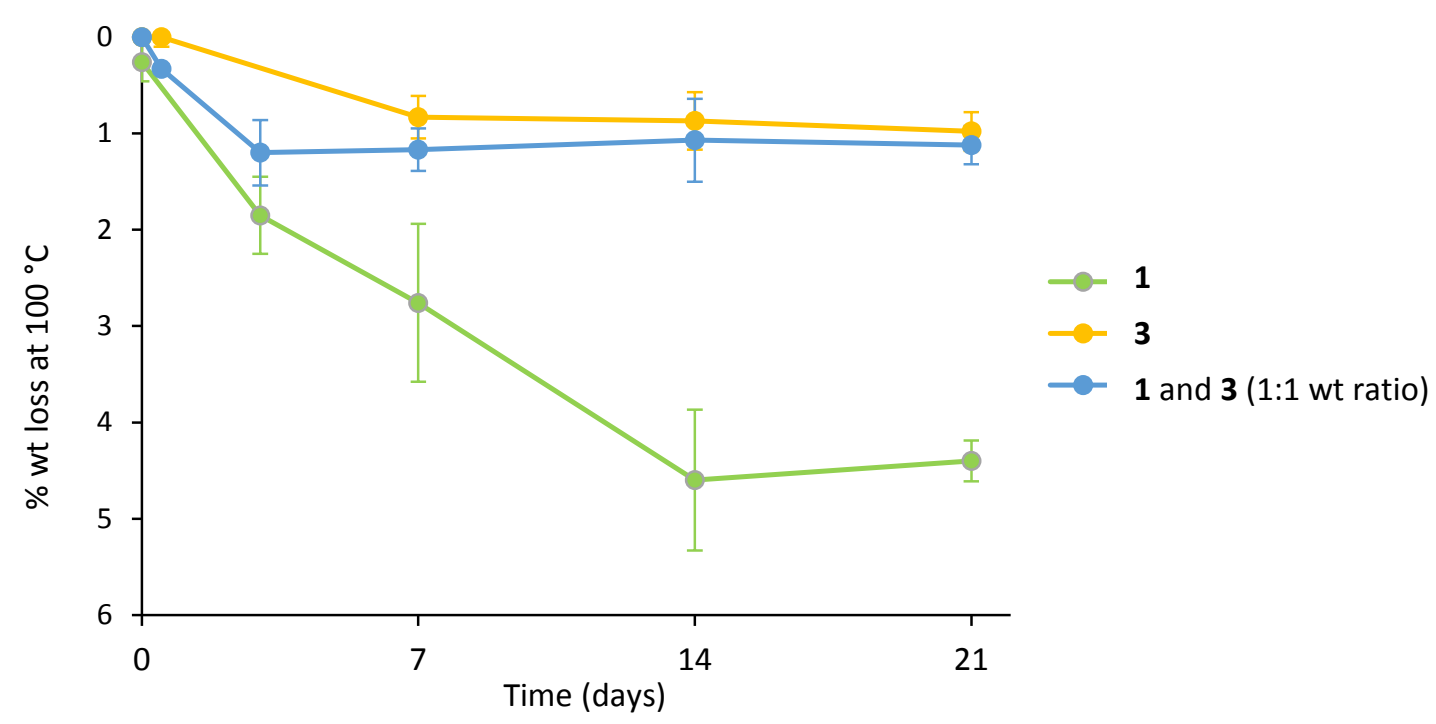

Figure 7. Percentage weight-loss monitored via thermogravimetric analysis (heating rate $2{ }^{\circ} \mathrm{C} / \mathrm{min}, 25-100{ }^{\circ} \mathrm{C}$ ) of functionalised PEGs $\mathbf{1}, \mathbf{3}$ and the blend of $\mathbf{1}$ and $\mathbf{3}$ (1:1 wt. ratio) at $100{ }^{\circ} \mathrm{C}$, as a function of time (days) of exposure to air before the measurement. Error bars show the standard error from three separate analyses.

After establishing the water absorption capabilities of these supramolecular polymer networks, discs (diameter $25 \mathrm{~mm}$, thickness $\sim 1 \mathrm{~mm}$ ) of material were cast from $\mathbf{1}, \mathbf{3}$ and the blend of $\mathbf{1}$ and $\mathbf{3}$ (1:1 wt. ratio) to investigate their potential for defect closure via swelling. The freshly-cast discs were placed between two sheets of porous $\mathrm{AWA}^{\circledR} 10$ non-woven polyester paper prior to analysis. Defects were introduced via three needle punctures $(0.8 \mathrm{~mm}$ diameter) through each cast (calculated to be equivalent to $0.3 \%$ removal of the surface area of each disc). The samples (still between sheets of polyester paper) were then placed in a stirred cell assembly in which a constant volume (10 mL) of water was maintained (Scheme 2 and SI Figure 33). Water passing through the punctures was then collected at timed intervals (every 2 minutes) and weighed to calculate the flow rate through the film (Figure 8). 


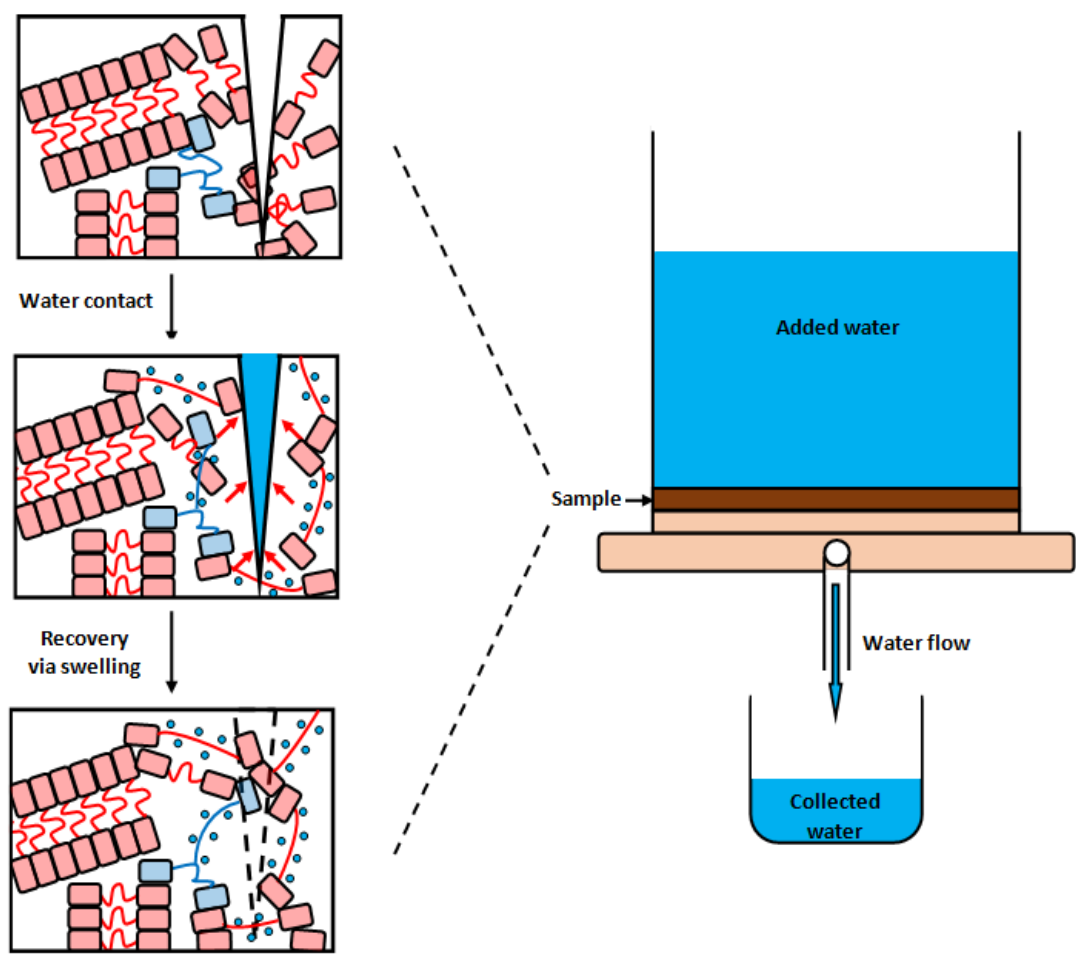

Scheme 2. Illustration of water flow under gravity through cast discs of $\mathbf{1}, \mathbf{3}$ and of blends of $\mathbf{1}$ and $\mathbf{3}$ (1:1 wt ratio), after introducing defects via puncturing, and recovery of discs' protective properties via swelling.

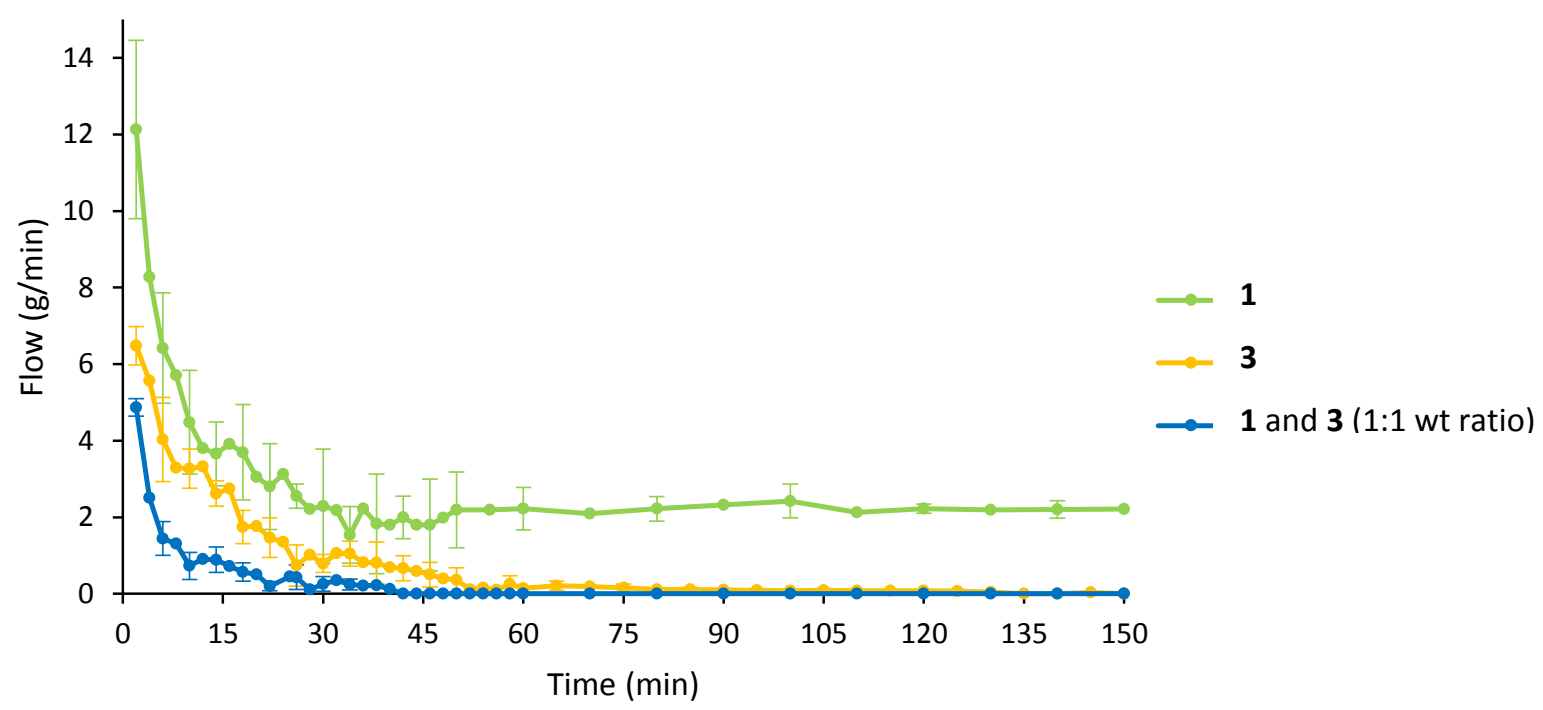

Figure 8. Flow rate of water under gravity as a function of time through cast discs of $\mathbf{1}, \mathbf{3}$ and of blends of $\mathbf{1}$ and $\mathbf{3}$ (1:1 wt. ratio), after introducing defects via puncturing (equivalent to removing $0.3 \%$ of the area of the disc). 
Films of the bi-functionalised PEG 1 were able to reduce the flow rate significantly (by a factor of about 7 over 60 minutes) but the flow then remained steady over a further 90 minutes (Figure 8). In contrast, the films formed from the tri-functionalised PEG 3 were able to halt the water flow completely after a period of 135 minutes (Figure 8). Most promisingly, films cast from blends of $\mathbf{1}$ and $\mathbf{3}$ (1:1 wt. ratio) showed highly efficient inhibition of water flow (to zero after ca. 42 minutes, Figure 8). Correspondingly, water absorption was monitored by disc volume expansion (monitored via average increase in thickness). Disc volume expansion after 180 minutes of liquid water contact showed that the discs cast from $\mathbf{3}$ experienced the largest increase (172\%), in contrast to results for water absorption from the atmosphere measured by TGA (Figure 7). Discs of $\mathbf{1}$ and of blends of $\mathbf{1}$ and $\mathbf{3}$ (1:1 wt, ratio) showed a 131\% and 163\% increase, respectively. Initial flow measurements were taken two minutes after defect formation to allow comparative water collection for each sample. Differences in initial flow are attributed to, and are in agreement with, the different response rates of the polymer blends (Figure 7).

Additionally, the water solubilities of the functionalised PEGs 1, 3 and of blends of $\mathbf{1}$ and $\mathbf{3}$ (1:1 wt. ratio) were monitored to ascertain if their ultimate failure to seal could be attributed to dissolution. Each cast film was placed in $\mathrm{D}_{2} \mathrm{O}$ and held at $40{ }^{\circ} \mathrm{C}$ for 1 month, but no dissolution was observed by ${ }^{1} \mathrm{H}$ NMR spectroscopy for any of the functionalised PEGs. It is therefore suggested that the results shown in Figure 8 results from the poor mechanical stability of films of the bi-functionalised PEG 1, rather than poor healability (see Figure $\mathbf{6}$ and SI) when compared to that of the tri-functionalised PEG $\mathbf{3}$ and the blend of $\mathbf{1}$ and $\mathbf{3}$, respectively.

\section{Conclusions}

A series of bi- and tri-armed functionalised PEGs end-capped with self-assembling nitroarylurea units has been synthesised. It is demonstrated that films cast from blends of these polymers possess self-repair capabilities at $20^{\circ} \mathrm{C}$. It is also shown that the self-repair properties of these films, as well as their mechanical and thermal stabilities, are dependent upon the amount and type of tri-armed functionalised PEG in the blend. Tri-armed functionalised PEGs with the nitro hydrogen-bond accepting moiety in the para position (relative to the urea group) form more stable films yet still possess self-repair properties. Those tri-armed units with the nitro groups in the meta- position increase mechanical stability but do not allow self-repair. Those films that demonstrate self-repair capabilities also display water absorption and swelling capabilities capable of defect/puncture closure. 


\section{Experimental}

Crystallographic Analysis. A crystal of 1-(4-aminophenyl)-3-(3'-nitrophenyl)urea (7) was mounted under Paratone-N oil and flash-cooled to $150 \mathrm{~K}$ under nitrogen using an Oxford Cryosystems Cryostream. Singlecrystal X-ray data were collected using an Agilent Gemini S-Ultra diffractometer with $\mathrm{Cu}-\mathrm{K} \alpha$ radiation $(\lambda$ $=1.54180 \AA$ ). The data were reduced using CrysAlisPro software. The structure was solved using the program Superflip ${ }^{41}$ and all non-hydrogen atoms were located. Least-squares refinements on $F$ were carried out using the CRYSTALS suite of programs. ${ }^{42}$ The non-hydrogen atoms were refined anisotropically. All the hydrogen atoms were located in difference Fourier maps, and those attached to $\mathrm{C}$ were then placed geometrically with a C-H distance of $0.95 \AA$ and assigned a $U_{\text {iso }}$ of 1.2 times the value of $U_{\text {eq }}$ of the parent $\mathrm{C}$ atom. The fractional coordinates of the $\mathrm{H}$ atoms attached to $\mathrm{C}$ were then refined with riding constraints. The coordinates of the hydrogen atoms attached to the $\mathrm{N}$ atoms were refined with a distance restraint of $\mathrm{N}$ $\mathrm{H}=0.86(1) \AA$ and with a $U_{\text {iso }}$ of 1.2 times the value of $U_{\text {eq }}$ of the parent $\mathrm{N}$ atom. The Flack parameter refined to $0.1(3)$, and so was fixed at 0.0 for later cycles of refinement.

Equipment. All chemicals and solvents were purchased from Sigma Aldrich and used as supplied unless otherwise specified. THF was distilled from sodium and benzophenone under an inert atmosphere prior to use. All other solvents were used as supplied. NMR spectra were obtained using Bruker Nanobay 400 and Bruker DPX 400 spectrometers (operating at $400 \mathrm{MHz}$ and $100 \mathrm{MHz}$ for ${ }^{1} \mathrm{H}$ NMR and ${ }^{13} \mathrm{C}$ NMR, respectively). All samples were prepared in either THF- $d_{8}$ or DMSO- $d_{6}$ and dissolution was achieved with slight heating and sonication (5-10 minutes). A Perkin Elmer 100 FT-IR (diamond ATR sampling attachment) was used for IR spectroscopic analysis. All solid film samples used for characterisation were cast from THF solution. Thermogravimetric Analysis employed a TA Instruments TGA Q50 system attached to TGA heat exchanger, a platinum crucible and an aluminium TA-Tzero pan (ramp rate $15^{\circ} \mathrm{C} / \mathrm{min}$ to $400{ }^{\circ} \mathrm{C}$ ). Differential scanning calorimetry was carried out using a TA DSC Q2000 with TA Refrigerated Cooling System 90 (aluminium TA-Tzero pans and lids) (ramp rate $15{ }^{\circ} \mathrm{C} / \mathrm{min}$ ). Rheological analysis employed a TA Instruments AR 2000 rheometer operating in parallel plate geometry (20 mm steel plates). Gel permeation chromatography (GPC) was carried out using an Agilent Technologies 1260 Infinity instrument, and the data were processed using Agilent GPC/SEC software; polystyrene standards was used as calibrants. Samples for GPC analysis were dissolved in analytical grade THF $(2 \mathrm{mg} / \mathrm{mL})$.

Synthesis; (1) Bis[1-(4-aminophenyl)-3-(3'-nitrophenyl)urea] poly(ethylene glycol) 600; 1-(4Aminophenyl)-3-(3-nitrophenyl)urea was synthesised as previously reported. ${ }^{30}$ Polyethylene glycol 600 diacyl chloride was generated according to the procedure described by Waite. ${ }^{21}$ Polyethylene glycol 600 diacyl chloride $(1.0 \mathrm{~g}, 1.6 \mathrm{mmol})$ was dissolved in anhydrous THF $(30 \mathrm{~mL})$ under inert conditions. To this, 
a solution of 1-(4-aminophenyl)-3-(3'-nitrophenyl)urea $(0.85 \mathrm{~g}, 3.1 \mathrm{mmol})$ and triethylamine $(0.5 \mathrm{~mL})$ in anhydrous THF $(30 \mathrm{~mL})$ was added dropwise under nitrogen and the mixture was stirred for 24 hours at room temperature. The bulk of the solvent was removed in vacuo and the resulting brown liquid was washed with water $(50 \mathrm{~mL})$, dried over magnesium sulfate, filtered and then evaporated under vacuum to yield the title compound as a brown solid; $(1.41 \mathrm{~g}, 76 \%) ; \mathrm{T}_{\mathrm{g}}-10{ }^{\circ} \mathrm{C}, \mathrm{T}_{\mathrm{deg}} 210{ }^{\circ} \mathrm{C}$; IR (ATR)/cm ${ }^{-1} ; 3353,3061,2871$, 1702, 1693, 1676, 1596, 1514, 1346, 1320, 1306, 1246, 1210, 1172, 1086, 1025, 1007, 991, 949, 9191, 891, 868, 828, 797, 734, 704; ${ }^{1} \mathrm{H}$ NMR (400 MHz, DMSO-d $)=9.53$ (s, 2H), 9.05 (s, 2H), 8.93 (s, 2H), $8.57(\mathrm{~s}, 2 \mathrm{H}), 7.83(\mathrm{~m}, 2 \mathrm{H}), 7.70(\mathrm{~m}, 2 \mathrm{H}), 7.56(\mathrm{~m}, 6 \mathrm{H}), 7.42(\mathrm{~m}, 4 \mathrm{H}), 4.17\left(\mathrm{~m}, 4 \mathrm{H}, \mathrm{H}_{\mathrm{i}}\right), 3.50(\mathrm{~m}$, integration obscured via water peak, $\left.\mathrm{H}_{\mathrm{k}, 1}\right) \mathrm{ppm} ;{ }^{13} \mathrm{C}$ NMR $\left(100 \mathrm{MHz}, \mathrm{DMSO}-d_{6}\right)=167.8,152.5,146.9,140.8,140.6$, $127.8,125.1,120.9,119.2,117.7,117.2,116.9,69.7$ ppm; GPC (THF) $M_{\mathrm{n}}=3200 \mathrm{Da}, M_{\mathrm{w}}=14900 \mathrm{Da}, Ð$ $=4.66$.

For the synthesis of tri-functionalised PEGs $\mathbf{2}$ and $\mathbf{3}$, glycerol ethoxylate ( $2 \mathrm{~g}, 2 \mathrm{mmol})$ was dissolved in THF (150 mL) under anhydrous conditions. To this solution, 4-nitrophenyl isocyanate (0.98 g, $6 \mathrm{mmol})$ was added and the mixture stirred for 24 hours at room temperature. The solvent was removed and the residue was washed with toluene $(2 \times 25 \mathrm{~mL})$ to give tris(4-nitrophenylcarbamato)glycerol ethoxylate as a yellow oil (2.9 g, 99\%); IR (ATR) /cm ${ }^{-1} 3351,3061,3030.2971,2978,2869$, 1732, 1702, 1686, 1676, 1596, 1554, 1508. 1444, 1367, 1346, 1322, 1261, 1212, 1172, 1055, 1026, 919, 858, 828, 753, 727; ${ }^{1} \mathrm{H}$ NMR (400 MHz, DMSO-d $)=10.52(\mathrm{~s}, 2 \mathrm{H}), 8.21(\mathrm{~m}, 6 \mathrm{H}), 7.71(\mathrm{~m}, 6 \mathrm{H}), 4.24(\mathrm{~m}, 6 \mathrm{H}), 3.53(\mathrm{~m}, 77 \mathrm{H})$ ppm; ${ }^{13} \mathrm{C}$ NMR $\left(100 \mathrm{MHz}, \mathrm{DMSO}-d_{6}\right)=153.2,154.6,141.6,152.0,117.6,70.4,70.1$, 69.7, 68.4, 64.2 ppm; GPC (THF) $M_{\mathrm{n}}=1700 \mathrm{Da}, M_{\mathrm{w}}=1900 \mathrm{Da}, Ð=1.12$. The tris(4-nitrophenylcarbamato) glycerol ethoxylate ( $2.9 \mathrm{~g}, 2 \mathrm{mmol})$ was then dissolved in THF:ethanol (50:50, $100 \mathrm{~mL})$, Pd-C added (0.05 g) and the mixture stirred under $\mathrm{H}_{2}$ for 24 hours at room temperature. The solution was filtered through Celite ${ }^{\circledR}(10 \mathrm{~g})$ and the solvent removed in vacuo to afford tris(4-aminophenylcarbamato) glycerol ethoxylate as a brown oil (2.8 g, 99\%); IR (ATR) /cm $\mathrm{cm}^{-1} 3355,2872,1713,1640,1594,1515,1433,1348,1225,1148,1096,1058,938$, 830, 757, 723; ${ }^{1} \mathrm{H}$ NMR (400 MHz, DMSO-d $)=9.19(\mathrm{~s}, 3 \mathrm{H}), 7.05(\mathrm{~m}, 6 \mathrm{H}), 6.48(\mathrm{~m}, 6 \mathrm{H}), 4.75(\mathrm{~s}, 6 \mathrm{H})$, $4.19(\mathrm{~m}, 6 \mathrm{H}), 3.55(\mathrm{~m}, 83 \mathrm{H}) \mathrm{ppm} ;{ }^{13} \mathrm{C}$ NMR (100 MHz, DMSO- $\left.d_{6}\right)=153.6,144.2,128.1,120.4,144.1$, $77.6,72.3,70.4,70.1,69.7,68.8,63.1,60.2 \mathrm{ppm}$; GPC (THF) $M_{\mathrm{n}}=1800 \mathrm{Da}, M_{\mathrm{w}}=2600 \mathrm{Da}, Ð=1.44$.

(2) Tris[1-(4-aminophenyl)-3-(3'-nitrophenyl)urea] glycerol ethoxylate; Tris(4-aminophenyl-carbamato) glycerol ethoxylate $1405 \mathrm{~g} / \mathrm{mol}(1.0 \mathrm{~g}, 0.7 \mathrm{mmol})$ was dissolved in anhydrous THF (50 mL) and 3nitrophenyl isocyanate $(0.35 \mathrm{~g}, 2.1 \mathrm{mmol})$ was added. The resulting solution was then stirred for 24 hours at room temperature. The solvent was removed in vacuo and the resultant oil washed with toluene to give the title compound as a red oil $(0.85 \mathrm{~g}, 64 \%) ; \mathrm{T}_{\mathrm{g}} 0{ }^{\circ} \mathrm{C}, \mathrm{T}_{\mathrm{deg}} 228{ }^{\circ} \mathrm{C}$; IR (ATR) / $\mathrm{cm}^{-1} 3352,3042,2926,2840$, 1650, 1593, 1500, 1444, 1411, 1387, 1328, 1260, 1236, 1149, 1010, 975, 936, 920, 829, 757, 721; ${ }^{1} \mathrm{H}$ NMR 
$\left(400 \mathrm{MHz}, \mathrm{DMSO}-d_{6}\right)=9.64(\mathrm{~s}, 3 \mathrm{H}), 9.16(\mathrm{~s}, 3 \mathrm{H}), 8.72(\mathrm{~s}, 3 \mathrm{H}), 8.57(\mathrm{~m}, 3 \mathrm{H}), 7.82(\mathrm{~m}, 3 \mathrm{H}), 7.81(\mathrm{~m}, 3 \mathrm{H})$, $7.57(\mathrm{~m}, 3 \mathrm{H}), 7.39(\mathrm{~m}, 12 \mathrm{H}), 4.19(\mathrm{~m}, 6 \mathrm{H}), 3.62(\mathrm{~m}, 90 \mathrm{H}) \mathrm{ppm} ;{ }^{13} \mathrm{C}$ NMR $\left(100 \mathrm{MHz}, \mathrm{DMSO}-d_{6}\right)=153.5$, 152.4, 148.1, 133.9, 130.0, 124.2, 121.1, 119.5, 119.3, 118.8, 118.7, 116.1, 77.6, 72.3, 70.4, 70.1, 69.7, $68.8,68.7,63.4,60.2,30.4$ ppm; GPC (THF) $M_{\mathrm{n}}=1400 \mathrm{Da}, M_{\mathrm{w}}=2500 \mathrm{Da}, \emptyset=1.79$.

(3) Tris[1-(4-aminophenyl)-3-(4-nitrophenyl)urea] glycerol ethoxylate; the triarmed functionalised PEG 3 was synthesised using same procedure as described for $\mathbf{2}$, but using 4-nitrophenyl isocyanate, to give the title compound as a brown highly viscous oil $(0.76 \mathrm{~g}, 57 \%)$; $\mathrm{T}_{\mathrm{g}}-9{ }^{\circ} \mathrm{C}, \mathrm{T}_{\mathrm{deg}} 236{ }^{\circ} \mathrm{C}$; IR (ATR) $/ \mathrm{cm}^{-1} 3351$, 3048, 2872, 1713, 1638, 1595, 1500, 1409, 1328, 1301, 1260, 1224, 1177, 1099, 1060, 1028, 936, 830, $720 ;{ }^{1} \mathrm{H}$ NMR $\left(400 \mathrm{MHz}, \mathrm{DMSO}-d_{6}\right)=9.67(\mathrm{~s}, 3 \mathrm{H}), 9.41(\mathrm{~s}, 3 \mathrm{H}), 8.82(\mathrm{~s}, 3 \mathrm{H}), 8.18(\mathrm{~m}, 6 \mathrm{H}), 7.67(\mathrm{~m}, 6 \mathrm{H})$, $7.39(\mathrm{~m}, 12 \mathrm{H}), 4.14(\mathrm{~m}, 6 \mathrm{H}), 3.54(\mathrm{~m}, 90 \mathrm{H}) \mathrm{ppm} ;{ }^{13} \mathrm{C} \mathrm{NMR}\left(100 \mathrm{MHz}, \mathrm{DMSO}-d_{6}\right)=140.7,126.4,125.1$, $121.4,119.1,118.3,117.8,117.2,115.2,112.3,77.6,72.3,70.4,70.1,69.7,68.7,63.4,60.2$ ppm; GPC (THF) $M_{\mathrm{n}}=1500 \mathrm{Da}, M_{\mathrm{w}}=2700 \mathrm{Da}, Ð=1.80$.

Compounds 4-6 were synthesised by an analogous route to that used for compound 1, where either 1-(4aminophenyl)-3-(4-nitrophenyl)urea (0.86 g, $3.2 \mathrm{mmol})$, 1-(4-aminophenyl)-3-phenylurea (0.73 g, 3.2 $\mathrm{mmol})$ or 3-nitroaniline $(0.44 \mathrm{~g}, 3.2 \mathrm{mmol})$ were added to polyethylene glycol 600 diacyl chloride $(1.0 \mathrm{~g}$, $1.6 \mathrm{mmol})$ and triethylamine $(0.5 \mathrm{~mL})$ in anhydrous THF $(30 \mathrm{~mL})$ under an inert atmosphere, to give compounds 4-6, respectively:

(4) Bis[1-(4-aminophenyl)-3-(4-nitrophenyl)urea] poly(ethylene glycol) 600; This was obtained as a brown, highly viscous oil; (1.55 g, 84\%); $\mathrm{T}_{\operatorname{deg}} 231^{\circ} \mathrm{C}$; IR (ATR) / $\mathrm{cm}^{-1}$; 3323, 3000, 2872, 1704, 1674, 1600, 1549, 1515, 1459, 1407, 1349, 1303, 1232, 1198, 1099, 945, 898, 838, 754, 654; ${ }^{1} \mathrm{H}$ NMR (400 MHz, DMSO- $\left.d_{6}\right)=9.54(\mathrm{~m}, 4 \mathrm{H}), 8.99(\mathrm{~s}, 2 \mathrm{H}), 8.20(\mathrm{~m}, 4 \mathrm{H}), 7.71(\mathrm{~m}, 4 \mathrm{H}), 7.59(\mathrm{~m}, 4 \mathrm{H}), 7.44(\mathrm{~m}, 4 \mathrm{H}), 4.06(\mathrm{~m}$, $\left.4 \mathrm{H}, \mathrm{H}_{\mathrm{g}}\right), 3.55(\mathrm{~m}, 66 \mathrm{H}) \mathrm{ppm} ;{ }^{13} \mathrm{C} \mathrm{NMR}\left(100 \mathrm{MHz}, \mathrm{DMSO}-d_{6}\right)=167.9,152.0,146.5,140.9,134.6,133.2$, $125.1,120.3,119.0,117.4,70.3,69.7,69.5 \mathrm{ppm}$; GPC (THF) $M_{\mathrm{n}}=8200 \mathrm{Da}, M_{\mathrm{w}}=22000 \mathrm{Da}, Ð=2.68$.

(5) Bis [1-(4-aminophenyl)-3-phenylurea] poly(ethylene glycol) 600; This was obtained as a yellow oil (1.20 $\mathrm{g}, 66 \%$ ); $\mathrm{T}_{\mathrm{deg}} 222{ }^{\circ} \mathrm{C}$; IR (ATR) $/ \mathrm{cm}^{-1} ; 3311,3055,2880,1712,1680,1602,1597,1559,1501,1410,1327$, $1305,1212,1203,1174,1111,1035,931,838,753,692 ;{ }^{1} \mathrm{H}$ NMR $\left(400 \mathrm{MHz}\right.$, DMSO- $\left.d_{6}\right)=9.50(\mathrm{~s}, 2 \mathrm{H}$, $\left.\mathrm{H}_{\mathrm{a}}\right), 8.79\left(\mathrm{~s}, 2 \mathrm{H}, \mathrm{H}_{\mathrm{b}}\right), 8.77\left(\mathrm{~s}, 2 \mathrm{H}, \mathrm{H}_{\mathrm{b}}\right), 7.53(\mathrm{~m}, 4 \mathrm{H}), 7.44(\mathrm{~m}, 4 \mathrm{H}), 7.38(\mathrm{~m}, 4 \mathrm{H}), 7.27(\mathrm{~m}, 4 \mathrm{H}), 6.96(\mathrm{~m}$, $2 \mathrm{H}), 4.06(\mathrm{~s}, 4 \mathrm{H}), 3.50\left(\mathrm{~m}\right.$, integration obscured via water peak) ppm; ${ }^{13} \mathrm{C}$ NMR $\left(100 \mathrm{MHz}, \mathrm{DMSO}-d_{6}\right)=$ 167.8, 152.6, 139.8, 135.6, 132.5, 128.7, 121.6, 120.3, 118.4, 118.0, 70.3, 70.1, 69.7, 69.5 ppm; GPC (THF) $M_{\mathrm{n}}=800 \mathrm{Da}, M_{\mathrm{w}}=1100 \mathrm{Da}, Ð=1.34$. 
(6) Bis[3-nitrophenylurea] poly(ethylene glycol) 600; This was obtained as a brown oil; (1.41 g, 73\%); $\mathrm{T}_{\text {deg }}$ $201{ }^{\circ} \mathrm{C}$; IR (ATR) /cm ${ }^{-1}$; 3451, 2874, 2692, 2512, 1739, 1705, 1607, 1517, 1483, 1408, 1349, 1310, 1235, 1090, 1036, 951, 838, 741, 677; ${ }^{1} \mathrm{H}$ NMR (400 MHz, DMSO-d $)=10.14$ (s, 2H), 8.67 (s, 2H), 7.99 (m, $2 \mathrm{H}), 7.93(\mathrm{~m}, 2 \mathrm{H}), 7.61(\mathrm{~m}, 2 \mathrm{H}), 4.13(\mathrm{~m}, 4 \mathrm{H}), 3.62(\mathrm{~m}, 31 \mathrm{H}) \mathrm{ppm} ;{ }^{13} \mathrm{C} \mathrm{NMR}\left(100 \mathrm{MHz}\right.$, DMSO-$\left.d_{6}\right)=$ $169.2,147.8,139.3,130.1,125.7,118.1,113.8,70.3,70.1,69.7,69.5$ ppm; GPC (THF) $M_{\mathrm{n}}=2900$ Da, $M_{\mathrm{w}}$ $=5200 \mathrm{Da}, Ð=1.79$.

\section{Acknowledgements}

The authors would like to acknowledge financial support from EPSRC and Gnosys Global Ltd (PhD studentship for BCB). In addition, the EPSRC is acknowledged for funding access to instrumentation in the Chemical Analysis Facility at the University of Reading.

\section{References}

(1) a) Cicchetti O. Mechanisms of oxidative photodegradation and of UV stabilization of polyolefins, Adv. Polym. Sci., 1970, 7, 70-112, b) Dissado L. A.; Fothergill G. C. Electrical degradation and breakdown in polymers, Peter Peregrinus Ltd., London, 1992, c) Vogelsang R.; Fruth B.; Farr T.; Fröhlich K., "European Transactions on Electrical Power", John Wiley \& Sons Ltd., Chichester, 2005, d) Baschek G.; Hartwig G.; Zahradnik F. Effect of water absorption in polymers at low and high temperatures, Polymer, 1999, 40, 3433-3441.

(2) Murphy, E. B.; Wudl, F. The World of Smart Healable Materials. Prog. Polym. Sci. 2010, 35, 223251.

(3) Wool, R. P. Self-Healing Materials: A Review. Soft Matter 2008, 4, 400-418.

(4) Burnworth, M.; Tang, L.; Kumpfer, J. R.; Duncan, A. J.; Beyer, F. L.; Fiore, G. L.; Rowan, S. J.; Weder, C. Optically Healable Supramolecular Polymers. Nature 2011, 472, 334-337.

(5) Hutchby, M.; Houlden, C. E.; Haddow, M. F.; Tyler, S. N. G.; Lloyd-Jones, G. C.; Booker-Milburn, K. I. Switching Pathways: Room-Temperature Neutral Solvolysis and Substitution of Amides. Angew. Chem., Int. Ed. 2012, 51, 548-551.

(6) Ying, H.; Zhang, Y.; Cheng, J. Dynamic Urea Bond for the Design of Reversible and Self-Healing Polymers. Nat. Commun. 2014, 5, 3218-3226.

(7) Bergman, S. D.; Wudl, F. Mendable Polymers. J. Mater. Chem. 2008, 18, 41-62.

(8) Greenland, B. W.; Burattini, S.; Hayes, W.; Colquhoun, H. M. Design, Synthesis and Computational Modelling of Aromatic Tweezer-Molecules as Models for Chain-Folding Polymer Blends. Tetrahedron 2008, 64, 8346-8354. 
(9) Cordier, P.; Tournilhac, F.; Soulié-Ziakovic, C.; Leibler, L. Self-Healing and Thermoreversible Rubber from Supramolecular Assembly. Nature 2008, 451, 977-980.

(10) a) Söntjens, S. H. M.; Sijbesma, R. P.; Van Genderen, M. H. P.; Meijer, E. W. Stability and Lifetime of Quadruply Hydrogen Bonded 2-Ureido-4[1H]-Pyrimidinone Dimers. J. Am. Chem. Soc. 2000, 122, 7487-7493, b) Isarea B.; Penseca S.; Raynala M., Bouteiller L. Bisurea-based supramolecular polymers: From structure to properties. C. R. Chim. 2016, 19, 148-156, c) Miyamae, K.; Nakahata, M; Takashima, Y.; Harada A. Self-Healing, Expansion-Contraction, and Shape-Memory Properties of a Preorganized Supramolecular Hydrogel through Host-Guest Interactions. Angewandte Chem. Int. Ed. 2015, 54, 8984-8987.

(11) Yang, Y.; Urban, M. W. Self-Healing Polymeric Materials. Chem. Soc. Rev. 2013, 42, 7446-7467.

(12) Greenland, B.; Hayes, W. Healable Polymer Systems; Royal Society of Chemistry, Cambridge, 2013.

(13) Hager, M. D.; Greil, P.; Leyens, C.; van der Zwaag, S.; Schubert, U. S. Self-Healing Materials, Vol. 22; Springer, Dordrecht, 2010.

(14) Ghosh, S. K. Self-Healing Materials: Fundamentals, Design Strategies, and Applications; WileyVCH, Weinheim, 2009.

(15) Ghosh, B.; Urban, M. W. Self-Repairing Oxetane-Substituted Chitosan Polyurethane Networks. Science, 2009, 323, 1458-1460.

(16) Burattini, S.; Greenland, B. W.; Merino, D. H.; Weng, W.; Seppala, J.; Colquhoun, H. M.; Hayes, W.; MacKay, M. E.; Hamley, I. W.; Rowan, S. J. A Healable Supramolecular Polymer Blend Based on Aromatic $\pi-\pi$ Stacking and Hydrogen-Bonding Interactions. J. Am. Chem. Soc. 2010, 132, 12051-12058.

(17) Li, Y.; Rios, O.; Keum, J. K.; Chen, J.; Kessler, M. R. Photoresponsive Liquid Crystalline Epoxy Networks with Shape Memory Behavior and Dynamic Ester Bonds. ACS Appl. Mater. Interfaces 2016, 8, 15750-15757.

(18) Yu, X.; Chen, L.; Zhang, M.; Yi, T. Low-Molecular-Mass Gels Responding to Ultrasound and Mechanical Stress: Towards Self-Healing Materials. Chem. Soc. Rev. 2014, 43, 5346-5371.

(19) Yanagisawa, Y.; Nan, Y.; Okuro, K.; Aida, T. Mechanically robust, readily repairable polymers via tailored noncovalent cross-linking. Science 2018, 359, 72-76.

(20) Xia, N. N.; Xiong, X. M.; Wang, J.; Rong, M. Z.; Zhang, M. Q. A Seawater Triggered Dynamic Coordinate Bond and Its Application for Underwater Self-Healing and Reclaiming of Lipophilic Polymer. Chem. Sci. 2016, 7, 2736-2742.

(21) Ahn, B. K.; Lee, D. W.; Israelachvili, J. N.; Waite, J. H. Surface-Initiated Self-Healing of Polymers in Aqueous Media. Nat. Mater. 2014, 13, 867-872. 
(22) Rose, S.; Prevoteau, A.; Elzière, P.; Hourdet, D.; Marcellan, A.; Leibler, L. Nanoparticle Solutions as Adhesives for Gels and Biological Tissues. Nature 2014, 505, 382-385.

(23) Meddahi-Pellé, A.; Legrand, A.; Marcellan, A.; Louedec, L.; Letourneur, D.; Leibler, L. Organ Repair, Hemostasis, and in vivo Bonding of Medical Devices by Aqueous Solutions of Nanoparticles. Angew. Chem., Int. Ed. 2014, 53, 6369-6373.

(24) White, S. R.; Sottos, N. R.; Geubelle, P. H.; Moore, J. S.; Kessler, M. R.; Sriram, S. R.; Brown, E. N.; Viswanathan, S. Autonomic Healing of Polymer Composites. Nature 2001, 409, 794-797.

(25) Zhang, M. Q.; Rong, M. Z. Intrinsic Self-Healing of Covalent Polymers through Bond Reconnection towards Strength Restoration. Polym. Chem. 2013, 4, 4878-4884.

(26) Harrington, M. J.; Masic, A.; Holten-andersen, N.; Waite, J. H.; Fratzl, H. Iron-Clad Fibers : A Metal-Based Biological Stratergy for Hard Flexible Coatings. Science, 2010, 328, 216-221.

(27) Harris, J. M. Poly(Ethylene Glycol) Chemistry: Biotechnical and Biomedical Applications; Plenum, New York, 1992.

(28) Rodríguez-Llansola, F.; Escuder, B.; Miravet, J. F.; Hermida-Merino, D.; Hamley, I. W.; Cardin, C. J.; Hayes, W. Selective and Highly Efficient Dye Scavenging by a pH-Responsive Molecular Hydrogelator. Chem. Commun. 2010, 46, 7960-7962.

(29) Wood, D. M.; Greenland, B. W.; Acton, A. L.; Rodríguez-Llansola, F.; Murray, C. A.; Cardin, C. J.; Miravet, J. F.; Escuder, B.; Hamley, I. W.; Hayes, W. PH-Tunable Hydrogelators for Water Purification: Structural Optimisation and Evaluation. Chem. Eur. J. 2012, 18, 2692-2699.

(30) Baker, B. C.; Acton, A. L.; Stevens, G. C.; Hayes, W. Bis Amide-Aromatic-Ureas - Highly Effective Hydro- and Organogelator Systems. Tetrahedron 2014, 70, 8303-8311.

(31) Hart, L. R.; Nguyen, N. A.; Harries, J. L.; Mackay, M. E.; Colquhoun, H. M.; Hayes, W. Perylene as an Electron-Rich Moiety in Healable, Complementary $\pi-\pi$ Stacked, Supramolecular Polymer Systems. Polymer, 2014, 69, 293-300.

(32) Hart, L. R.; Hunter, J. H.; Nguyen, N. A.; Harries, J. L.; Greenland, B. W.; Mackay, M. E.; Colquhoun, H. M.; Hayes, W. Multivalency in Healable Supramolecular Polymers: The Effect of Supramolecular Cross-Link Density on the Mechanical Properties and Healing of Non-Covalent Polymer Networks. Polym. Chem. 2014, 5, 3680-3688.

(33) Zhao, H.; Liu, Z.; Piao, L. Preparation and Characterization of PEG/PLLA Multiblock and Triblock Copolymers. Bull. Korean Chem. Soc. 2012, 33, 1638-1642.

(34) You, Y.; Bertram, A. K. Effects of Molecular Weight and Temperature on Liquid-Liquid Phase Separation in Particles Containing Organic Species and Inorganic Salts. Atmos. Chem. Phys. 2015, $15,1351-1365$. 
(35) Steed, J. W. Anion-Tuned Supramolecular Gels: A Natural Evolution from Urea Supramolecular Chemistry. Chem. Soc. Rev. 2010, 39, 3686-3699.

(36) Kumar, D. K.; Jose, D. A.; Das, A.; Dastidar, P. First Snapshot of a Nonpolymeric Hydrogelator Interacting with Its Gelling Solvents. Chem. Commun. 2005, 4059-4061.

(37) Schreiner, R. P. Metal-Free Organocatalysis through Explicit Hydrogen Bonding Interactions. Chem. Soc. Rev. 2003, 32, 289-296.

(38) Kuzmic, P. Program DYNAFIT for the Analysis of Enzyme Kinetic Data: Application to HIV Proteinase. Anal. Biochem. 1996, 237, 260-273.

(39) Sijbesma, R. P.; Beijer, F. H.; Brunsveld, L.; Folmer, B. J.; Hirschberg, J. H.; Lange, R. F.; Lowe, J. K.; Meijer E. W.; Reversible Polymers Formed from Self-Complementary Monomers Using Quadruple Hydrogen Bonding. Science 1997, 278, 1601-1604.

(40) Berl, V.; Schmutz, M.; Krische, M. J.; Khoury R. G.: Lehn J. M.; Supramolecular Polymers Generated from Heterocomplementary Monomers Linked through Multiple Hydrogen-Bonding Arrays - Formation, Characterization, and Properties. Chem. Eur. J., 2002, 8, 1227-1244.

(41) Palatinus, L.; Chapuis, G. SUPERFLIP - A Computer Program for the Solution of Crystal Structures by Charge Flipping in Arbitrary Dimensions. J. Appl. Crystallogr. 2007, 40, 786-790.

(42) Betteridge, P. W.; Carruthers, J. R.; Cooper, R. I.; Prout, K.; Watkin, D. J. CRYSTALS Version 12: Software for Guided Crystal Structure Analysis. J. Appl. Crystallogr. 2003, 36, 1487-1487. 